GINECOLOGIA PRACTICA para estudiantes y médicos 



\section{GINECOLOGIA PRACTICA}

por el

Prof. Dr. Med. y Fil. W. PSCHYREMBEL de Berlin

Con 503 figuras en negro y color

EDITORIAL ALHAMBRA, S. A.

MADRID - BARCELONA - BUENOS AIRES - MEXICO 
Edición original:

PRAKTISCHE GYNÄKOLOGIE

für Studierende und Ärzte

(C) WALTER DE GRUYTER \& CO.

BERLIN

Primera edición española, 1969

(C) EDITORIAL ALHAMBRA, S. A.

R. E. 182

Madrid - 1. Claudio Coello, 76

Traducción directa del alemán por el

Dr. F. RUIZ TORRES

Depósito legal: M. $18477 \cdot 1969$

Impreso en España-Printed in Spain 
No olvide, al explorar mediante la inspección, la palpación y la combinación de ambos métodos, que se encuentra ante usted una persona que padece y que, a veces, ya está marcada por la muerte y entregada a ella. No abandone nunca la falta de consideración de la investigación, que puede ser eficaz para usted en el establecimiento de un diagnóstico seguro, adquiriendo superioridad sobre la situación médica humana. Ejercitese a tiempo en el cuidado del interrogatorio, en la sutilidad de oir y comprender, incluso los apuros insinuados solamente, en el sentir $y$ entender miedos futuros no expresados, en ser indulgente contra la dureza, incomprensión y renitencia frente a los consejos del médico, nacidas de tal miedo. Piense usted siempre en la posibilidad de que su madre, su hermana, su esposa o su prometida le fueran entregadas a vida o muerte, $y$ por ello tiene que conocer lo que depende de cada palabra, lo que falta en el lecho de la paciente y lo que significa cada contacto que afecte al cuerpo enfermo.

WALter Stoeckel (1871-1961).

Toda consulta médica tiene que ser un centro de lucha contra el cáncer.

Heinrich Martius.

El cáncer es curable, si se reconoce a tiempo.

Hans Runge.

La lucha contra el cáncer requiere una gran organización.

AUgust Bier.

$N i$ una sola mujer en el mundo debe morir por un cáncer de útero, si se utilizan a tiempo todos los métodos para su profilaxis y su diagnóstico precoz.

Dr. John Heller, Director del Memorial Sloan Kettering Cancer Institute, Nueva York (el mejor centro del mundo para la investigación del cáncer).

Este conocimiento cientifico se ha generalizado hasta entre los más jóvenes estudiantes de Medicina de cursos clínicos: la 
esencia del diagnóstico precoz consiste, recientemente, en reconocer y descubrir las modificaciones cancerosas en el cuello uterino, en su periodo más inicial $y$, a ser posible, cuando estas alteraciones se encuentren limitadas localmente todavia dentro del epitelio superficial, es decir,

antes de que el cáncer prolifere destruyendo el tejido conjuntivo,

antes de que produzca sintomas percibidos por la mujer, antes de que la propagación del cáncer comience en los alrededores más o menos lejanos del cuello uterino (pág. 79).

Estos conocimientos son de una importancia decisiva en todo el mundo, para la salud y la vida de las mujeres. Un candidato que pretenda aprobar su examen sin que exprese con claridad estos conceptos, tiene que ser reprobado por el examinador, por dictado de conciencia.

En toda exploración ginecológica y "muy especialmente en toda hemorragia ginecológica, debe pensarse, en primer lugar, en un cáncer". El hecho de que un cáncer pase inadvertido no puede ser corregido nunca.

(págs. 132-133)

La suerte de la mujer "depende de si su médico da o no" los tres primeros pasos decisivos: $1 .{ }^{\circ}$, pensar siempre en un cáncer; $2 .^{\circ}$, explorar siempre el hocico de tenca y la vagina con el espéculo; $3 .^{\circ}$, por lo menos una vez al año hacer un frotis.

(pág. 133)

Los ginecólogos no están solamente para tratar el cáncer, sino, en primer lugar, para evitarlo.

(pág. 77)

Una exploración ginecológica "sin frotis citológico o sin exploración colposcópica" debe ser considerada hoy como incompleta.

(pág. 132)

Un cuello uterino sano "es una de las principales condiciones previas" para unos órganos genitales sanos.

(pág. 70) 